\title{
An application of Premack's theory to behaviors associated with a FFI food schedule'
}

ROBERT W. SCHAEFFER, JUDITH C. DIEHL AND CHARLES L. SALZBERG

FLORIDA STATE UNIVERSITY

Four female rats were trained to lever-press on a FR 100 food schedule, then switched to a FFI 45-sec. food schedule. Water was freely available in both schedules. Lever-pressing was more probable than drinking in the FR 100, but the inverse was obtained in the FFI. This indicated that although adventitious reinforcement occurred in the FFI, drinking and lever-pressing in the FFI could not be attributed to the same reinforcement contingency.

Considerable interest has been expressed recently regarding the factors responsible for the development of excessive drinking in animals exposed to timedependent (i.e., VI, FI) food reinforcement schedules. Falk (1961), who discovered the phenomenon, has suggested that schedule-induced polydipsia (SIP) is neither acquired nor maintained by adventitious reinforcement. Both Falk (1966) and Stein (1964) have presented data which indicate that SIP is attributable solely to prandial thirst factors, since drinking typically occurs following, rather than prior to or coincidental to pellet ingestion, as would be required if drinking were a food-reinforced response. Segal \& Holloway (1963) have agreed that drinking is originally initiated by prandial thirst factors, but have presented data which suggest that excessive drinking is generated and maintained only when the drinking response becomes part of a chain of instrumental responses which terminates with, and thus is reinforced by, pellet delivery.

The behavioral effects of time-dependent reinforcement schedules are of particular interest when formulated within the context of Premack's (1965) differential response rate reinforcement theory. Working within the context of Premack's theory, Schaeffer (1965) obtained evidence that asymptotic reinforced instrumental response rates vary directly with the precontingent instrumental response rates, under conditions where the rate of the reinforcing response is held constant. This finding suggests a procedure for examining the potential reinforcement effects of time-dependent food reinforcement schedules.

Consider an experiment in which drinking and leverpressing responses are concurrently and freely available to Ss exposed to a free fixed interval (FFI) food reinforcement schedule in which food pellets are dispensed at fixed time intervals, independently of the $S$ 's behavior. Further consider that lever pressing (a) is like drinking in that it has no programmed relation to pellet delivery, (b) is unlike drinking in that it has no appetitional or thirst basis, (c) is more probable than drinking, thereby increasing the probability that it, rather than drinking, will be reinforced by pellet de- livery, and (d) is exposed to the same rate of the potentially reinforcing food response as is drinking. Since it is well established that SIP is generated by FFI food reinforcement schedules, two dichotomous outcomes a re suggested by this type of experiment. On one hand, if neither behavior which occurs in the FFI inter-pellet interval is under the direct control of an adventitious food reinforcement contingency, then leverpressing should extinguish, while the thirst-induced behavior, polydipsia, should be acquired. On the other hand, if both behaviors are under the direct control of an adventitious food reinforcement contingency, then both behaviors should be maintained by the FFI reinforcement schedule and drinking, the less probable response, should show a lower asymptotic rate than lever-pressing, the more probable response.

The present experiment, in which lever-pressing was built to a higher rate than drinking by training rats to press on a FR 100 food reinforcement schedule prior to exposing them to a FFI 45 sec. food schedule, was designed to provide information on this problem.

\section{Method}

The Ss were four female Sprague Dawley rats, about 120 days old at the beginning of the experiment. Each $S$ was individually housed. Water was always available in the home cage and in the test chamber.

The test chambers were standard LVE Model 1316 rat test compartments, modified by installation of a $100 \mathrm{ml}$ graduated tube in place of the right lever. The test conditions were programmed by standard electromechanical devices. Lever-presses, pellet delivery, and licks on the water tube were recorded on counters. Water consumption was measured from the calibrated water tubes.

All Ss were maintained for four weeks on ad lib water and food in the home cages, then shifted to a $21 \mathrm{hr}$. food deprivation schedule for three weeks. Thereafter, each $S$ obtained its entire daily food ration in the test chamber during the 175-185 min. test sessions which were run daily, seven days a week.

The Ss were magazine trained, then shaped to press for the standard $45 \mathrm{mg}$ Noyes food pellets that were used as reinforcements. The FR lever requirement was then progressively raised to $\mathrm{FR} 100$. When responding on the FR 100 had stabilized, the Ss were switched to an FFI 45 sec. food reinforcement schedule for 14 consecutive days.

\section{Results and Discussion}

The results of the experiment are summarized in Table 1, which presents the mean time that each $\mathrm{S}$ spent lever-pressing and drinking in the last seven sessions 
Table 1. Mean sec. spent lever-pressing (L. P.) and drinking (D) during the last seven days of a FR 100 lever-press-for-food contingency and during the first and last seven days of a subsequent FFI 45 sec. food schedule. All values are rounded to the nearest sec.

\begin{tabular}{lrrrrrr} 
& \multicolumn{3}{c}{$\begin{array}{c}\text { Type of Schedule } \\
\text { FFI ( } 100\end{array}$} & \multicolumn{2}{c}{ FFI (2) } \\
\hline Ss & L.P. & D & L. P. & D & L. P. & D \\
\hline S1 & 5345 & 833 & 1398 & 2417 & 485 & 3167 \\
S2 & 6122 & 750 & 1424 & 2042 & 2475 & 2958 \\
S3 & 6507 & 1417 & 1992 & 2833 & 2283 & 2792 \\
S4 & 5316 & 791 & 1969 & 2208 & 2889 & 3708 \\
\hline
\end{tabular}

of the FR 100 lever-pressing food contingency, and in the first and last seven sessions of the FFI food schedule. Since the rat licks at a constant 6 licks/sec. (cf., Schaeffer \& Premack, 1961) mean sec. spent licking were computed by dividing mean total licks in each seven-day period by six. Mean time spent lever-pressing was obtained by repeatedly sampling each S's momentary lever-pressing response rate, then dividing each S's mean total presses in each seven-day period by its respective momentary pressing rate.

As is evident from the data in Table 1, mean time spent lever-pressing in the FR 100 food contingency exceeded mean time spent licking in that period. Mean time spent in lever-pressing in both FFI periods was less for all Ss than mean time spent lever-pressing in the FR 100 food contigency. Lever-pressing did not extinguish when the FR 100 food contingency was removed, however, for all Ss engaged in sustained leverpressing during both FFI periods. Total daily leverpresses emitted by Ss $1,2,3$, and 4 in the last seven days of the FR 100 food contingency sessions frequently exceeded $21,24,26$, and 21 thousand, respectively. During the last seven sessions of the FFI, total daily lever-presses for these Ss exceeded 2, 10, 16, and 14 thousand, respectively. In this same period, all Ss drank in excess of $70 \mathrm{ml}$ of water daily.

The results of this experiment are not in complete accord either with a simple thirst-induced explanation of SIP, nor with a simple adventitious reinforcement explanation of SIP. The fact that lever-pressing, which cannot be explitined on a thirst-induced basis, was maintained at a high rate in the FFI condition indicates that reinforcement does have a direct effect on behaviors occurring in the inter-pellet interval. The fact that lever-pressing time in the FFI was less than drinking time in the FFI, however, suggests that both behaviors were not under the control of identical reinforcement consequences. Had both behaviors been under the control of the same reinforcement consequences, lever-pressing, the most probable response, should have been maintained at a higher rate in the FFI than drinking, the less probable response (Schaeffer, 1965). In this context, the present results intimate that SIP may be explicable on the basis of combinatory adventitious reinforcement and thirst-induced motivational effects, whereas leverpressing may be attributed to adventitious reinforcement alone. As Falk (1966) has indicated, however, a precise distributional response analysis is prerequisite to determining whether responses occurring in the interpellet interval can reasonably be attributed to the consequences of a reinforcement contigency, or must be attributable to factors other than reinforcement. $\mathrm{Al}-$ though the present study was not instrumented to record a distributional response analysis, observation indicated that drinking was typically confined to the $30-\mathrm{sec}$. perioc following pellet delivery, while lever-pressing typically occurred only in the $15-$ to $20-\mathrm{sec}$. period preceding pellet delivery. Further studies, now in progress, should permit more precise specification of the sequential and temporal relationships between pellet delivery and the responses which occur in the inter-pellet interval. and hopefully, shed further light on the factors responsible for initiating and maintaining thirst and non-thirst related behaviors in time-dependent food schedules.

\section{References}

Falk, J. L. Production of polydipsia in normal rats by an intermittent food schedule. Science, 1961, 133, 195-196.

Falk, J. L. Schedule-induced polydipsia as a function of fixed interval length. J. exp. Anal. Behav., 1966, 9, 37-39.

Premack, D. Reinforcement theory. In Nebraksa Symposium on Motivation, 1965. Lincoln: University Nebraska Press, 1965. Schaeffer, $\mathbf{R}$. W. The reinforcement relation as a function of instrumental response base rate. J. exp. Psychol., 1965, 69, 419-425.

Schaeffer, R. W., \& Premack, D. Licking rates in infant albino rats. Science, 1961, 134, 1980-1981.

Segal, E. F., \& Holloway, S. M. Timing behavior in rats with water drinking as a mediator. Science, 1963, 140, 888-889.

Stein, L. Excessive drinking in the rat: Superstition or thirst? $J$. comp. physiol. Psychol., 1964, 58, 237-242.

\section{Note}

1. Supported in part by Public Health Service Research Grants MH-08775 and MH-12025, from the National Institute of Mental Health. 